\title{
Desenvolvimento de fornecedores: um estudo de caso utilizando a troca rápida de ferramentas
}

\author{
Carla Simone Ruppenthal Neumann, M. Eng. \\ LOPP/PPGEP - Escola de Engenharia da UFRGS \\ E-mail: carlarup@producao.ufrgs.br \\ José Luis Duarte Ribeiro, Prof. Dr. \\ LOPP/PPGEP - Escola de Engenharia da UFRGS \\ E-mail: ribeiro@.ufrgs.br
}

\begin{abstract}
Resumo
Devido ao aumento da competitividade entre as empresas, torna-se cada vez mais importante obter vantagens, principalmente se os benefícios puderem ser estendidos aos diversos elementos da cadeia de fornecimento. 0 objetivo deste trabalho é apresentar um programa de desenvolvimento de fornecedores. Este programa partiu da necessidade de uma empresa montadora de máquinas agrícolas melhorar o desempenho de seus fornecedores, auxiliando-os a obter melhorias nos processos e operações. As ações desenvolvidas em um fornecedor, tomando como base a troca rápida de ferramentas (TRF), são descritas e discutidas, bem como os resultados obtidos.
\end{abstract}

Palavras-chave

Desenvolvimento de fornecedores, troca rápida de ferramentas, cadeia de fornecimento.

\section{Supply chain development: a case study appling the single minute exchange of die technique}

\begin{abstract}
Due to the increasing concurrence among companies, looking for production advantages is of paramount importance, mainly if the benefits are such that they can be extended to all levels of the supply chain. The aim of this paper is to present a program for suppliers development. The program was designed by an automotive company facing the need of increasing the overall capacity of its suppliers, helping them to achieve improvements in operations and processes. The actions conducted in one of the suppliers, contemplating the single minute exchange of die, are described and discussed, as well as the obtained results.
\end{abstract}

Key words

Supplier development, single minute exchange of die, supply chain. 


\section{INTRODUĈ̣̃O}

Vivenciamos uma era marcada pela pressão competitiva. A necessidade de melhorar ou modificar o processo nunca foi tão urgente quanto agora (CHANDRASHEKAR; e CALLARMANN, 1998). Nos últimos quinze anos, tem havido um grande crescimento no conhecimento e nas atividades globais relacionadas ao gerenciamento da qualidade e ao papel dos clientes e fornecedores (BIEHL, 2000). Segundo Campos (1992), uma empresa não pode ser competitiva de forma isolada. Ela faz parte de uma cadeia de compradores e fornecedores, onde todas as empresas da cadeia buscam a máxima taxa de valor agregado, repassando ganhos de custo e qualidade, de forma a tornar toda a cadeia competitiva.

De acordo com Krause; Ellram (1997a), devido à incerteza de encontrar uma fonte melhor de fornecimento e ao alto custo para pesquisar e avaliar novos fornecedores, as empresas precisam encontrar meios de melhorar seu desempenho utilizando seus atuais fornecedores. Como consequiência, afirmam que é essencial desenvolver o relacionamento entre as partes. O envolvimento e a parceria com os fornecedores leva a uma entrega de materiais com qualidade e no tempo certo, podendo, inclusive, facilitar o desenvolvimento de novos produtos (CRAWFORD; COX, 1991). Keough (1994) afirma que, quando uma empresa alcança os padrões mundiais, sua tarefa seguinte é auxiliar seus fornecedores a alcançar os mesmos níveis. Estes níveis incluem melhorias contínuas nos custos, na qualidade e nos tempos de atravessamento.

Neumann (2002) descreve uma forma de auxiliar as empresas e os fornecedores a melhorar o seu relacionamento, estabelecendo as etapas de um programa de desenvolvimento de fornecedores. Salienta que os resultados alcançados após a intervenção foram positivos e reforçam a necessidade deste tipo de programas.

Este trabalho pretende expor a temática do desenvolvimento de fornecedores utilizando a troca rápida de ferramentas (TRF) como forma de melhorar o desempenho dos fornecedores e a competitividade da cadeia. Inicialmente, serão descritas as ações de um programa de desenvolvimento de fornecedores conduzido pela empresa que está no topo da cadeia produtiva e, após, a implementação prática do programa será exemplificada através das ações realizadas em um fornecedor.

\section{DESENVOLVIMENTO DE FORNECEDORES}

Segundo Watts; Hahn (1993), Carter et al. (1998) e Humphreys et al. (2001), o relacionamento tradicional entre empresas compradoras e seus fornecedores tem sido caracterizado como de disputa entre adversários, baseada em fornecedores múltiplos, oferta competitiva e o uso de tempos de contrato curtos. Por outro lado, Leenders (1989) afirma que há duas forças que estão aumentando o envolvimento dos compradores com os fornecedores: o aumento da taxa de novos produtos e processos e a expansão do mercado internacional. Muitas empresas estão reconhecendo que sua habilidade de se tornar competidores de classe mundial está baseada, em grande parte, na sua habilidade de estabelecer altos níveis de confiança e cooperação com seus fornecedores, estabelecendo parcerias (HUMPHREYS et al., 2001). Percebe-se uma nova tendência nas relações entre compradores e fornecedores: o gerenciamento de fornecedores geograficamente dispersos, que formam uma rede, e a valorização da qualidade e da entrega a tempo, não apenas do custo (KEOUGH, 1994).

De acordo com o sentido que foi adotado nos trabalhos de Leenders (1989), Krause (1997), Krause e Ellram (1997a e 1997b), Krause et al. (1998), Krause (1999), Handfield et al. (2000) e De Toni e Nassimbeni (2000), o termo desenvolvimento de fornecedor refere-se a qualquer esforço realizado por uma empresa compradora junto a um fornecedor, para aumentar seu desempenho e capacidade, a fim de atender às necessidades de suprimento de longo e curto prazo da empresa compradora. $\mathrm{O}$ desenvolvimento de fornecedores pode abranger, desde esforços limitados, como avaliar superficialmente o fornecedor e exigir aumento de desempenho, quanto esforços extensivos, como, por exemplo, treinamento do pessoal do quadro funcional do fornecedor e investimento nas operações do mesmo. Existem muitos elementos críticos que surgem ao longo dos esforços dirigidos ao desenvolvimento de um fornecedor: a efetividade da via de comunicação, a avaliação do fornecedor e respectivo feedback, o foco no custo total (e não somente no preço) e a perspectiva de longa duração.

Krause (1997) e Hahn et al. (1990) concordam que um dos objetivos primários do setor de compras é manter uma rede de fornecedores capacitados. Isso significa que a habilidade de uma empresa em produzir produtos de qualidade, a um preço razoável, no tempo certo, é um fator fortemente influenciado pela capacidade dos fornecedores. Conseqüentemente, sem uma rede de fornecedores competentes, a competitividade da empresa pode cair significativamente. Assim, quando um fornecedor é incapaz de corresponder às necessidades do comprador, o comprador tem algumas alternativas: internalizar o item que estava sendo produzido pelo fornecedor externo, mudar para um fornecedor mais capaz, ajudar a melhorar a capacidade dos fornecedores atuais ou realizar uma combinação destas três alternativas 
(HANDFIELD et al., 2000 e KRAUSE et al., 1998).

Watts e Hahn (1993) concluíram que, infelizmente, os compradores que estão utilizando programas para desenvolvimento dos fornecedores estão interessados em melhorar o produto que comercializam, em vez de auxiliar a melhorar a capacidade de seus fornecedores. Assim, pode-se concordar com Krause (1997), quando afirma que os benefícios de um programa de parceria precisam ser balanceados, ao contrário do cenário usual, onde o cliente (comprador) recebe muitos benefícios e o fornecedor poucos. O sucesso continuado e duradouro de uma aliança estratégica com o fornecedor dependerá largamente do fluxo de informações técnicas trocado entre o comprador e o fornecedor (MOHR; SPEKMAN, 1994; STUART; MCCUTCHEON, 1996; KRAUSE, 1999; GRIFFITHS; MARGETTS, 2000; e MILGATE, 2001). Blenkhorn e Leenders (1988) comentam que os fornecedores geralmente só produzem de acordo com o que lhes é exigido. Como consequiencia, as empresas compradoras merecem o que elas recebem dos fornecedores, pois não exigiram mais. Somente esperando mais dos fornecedores, explicitando melhor essas expectativas e sendo capaz de participar nos esforços de desenvolvimento do fornecedor, é que as empresas compradoras podem esperar desenvolver sua base de fornecimento para competir num mundo cada vez mais globalizado (KRAUSE; ELLRAN, 1997a).

\section{TROCA RÁPIDA DE FERRAMENTAS (TRF)}

Conforme Kannenberg (1994), o tempo de preparação ou de setup é o intervalo de tempo que se leva desde o término da última peça boa do lote anterior até a saída da primeira peça boa do próximo lote. Em outras palavras, pode-se dizer que é o tempo necessário para preparar os operadores e os equipamentos para a fabricação de outro produto pertencente ao mix global de produção.

Existem dois tipos de operação de setup: o setup interno, no qual as operações podem ser executadas somente quando a máquina está parada, e o setup externo, cujas operações podem ser realizadas enquanto a máquina ainda está em funcionamento. Como exemplos de setup interno podem ser citadas a fixação e a remoção de matrizes e como exemplos de setup externo podem ser citados o transporte de matrizes e a sua montagem (SHINGO, 2000).

A TRF foi desenvolvida por Shingo num período de 19 anos, como resultado de análise detalhada de aspectos teóricos e práticos que envolvem as operações de setup. Compreende quatro estágios conceituais de melhoria (SHINGO, 1996a, 1996b e 2000). No estágio inicial (estágio "zero"), as condições de setup interno e externo não se distinguem, se confundem. O que poderia ser realizado externamente é realizado internamente e, por isso, as máquinas ficam paradas por longos períodos. O primeiro estágio da TRF separa o setup interno do externo. Este é um dos passos mais importantes da TRF, pois a preparação de componentes e a manutenção não devem ser realizadas com a máquina parada. O segundo passo da TRF converte o setup interno em externo. Este estágio envolve duas noções muito importantes. Uma, é a de reexaminar as operações para verificar se algum passo foi erroneamente tomado como interno. A outra diz respeito a encontrar meios (soluções tecnológicas) para converter estes passos para setup externo. É comum verificar que as operações que são realizadas atualmente como setup interno podem, muitas vezes, ser convertidas para externas reexaminando a sua real função. O terceiro passo da TRF racionaliza todos os aspectos da operação de setup. Leva em consideração a eliminação de ajustes e a linearização dos métodos de fixação. A maneira mais rápida de trocar uma ferramenta é não ter de trocá-la.

O trabalho de Mc Intosh et al. (2000) faz críticas ao trabalho desenvolvido por Shingo. Afirma que na prática da indústria deve haver um certo grau de flexibilidade no uso da metodologia, pois certas técnicas serão enfatizadas em detrimento de outras, e alguns estágios individuais não serão utilizados na seqüência prescrita. Por outro lado, sugere que a metodologia contemple o projeto, realizando, por exemplo, mudanças de desenho de equipamento de processo ou mudanças no projeto de produtos em manufatura.

A literatura enfatiza as vantagens da redução do tempo de setup no chão-de-fábrica em muitos casos reais, conforme pode ser visto em Rehman e Diehl (1993), Kannenberg (1994), Venjara (1996), Guanasekaran; Cecille (1998), Moxham; Greatbanks (2001) e Patel et al. (2001a e 2001b). Embora a prática industrial japonesa leve em conta as propostas teóricas de Shingo (1996a e 2000), Monden (1981) e Hay (1987), entre outros, é necessário considerar que, na indústria brasileira, mais especificamente, em pequenos fornecedores, muitos dos conceitos acima citados ainda são novidade.

De acordo com Shingo (2000), as vantagens proporcionadas pela implantação da TRF são: rapidez e facilidade nas tarefas de setup e troca de produtos com redução de custos, aumento da capacidade produtiva, aumento da taxa de utilização das máquinas e redução de tempos mortos, facilidade de produção de mix variado de produtos em curto espaço de tempo, flexibilidade e rapidez nas alterações de produtos, trabalho com lotes menores, diminuição do tempo de resposta, redução dos estoques intermediários, redução do tempo de atravessamento, 
uso mais racional e efetivo do espaço do chão de fábrica, geração de ganhos em qualidade, redução de custos pela eliminação de retrabalho e desperdícios de materiais, entre outras.

\section{ETAPAS DO PROGRAMA DE DESENVOLVIMENTO DE FORNECEDORES JUNTO À EMPRESA}

Inicialmente a empresa manteve contato com a universidade (autores), solicitando auxílio para o trabalho junto aos fornecedores. Todas as etapas foram executadas a partir de reuniões com a gerência do setor de Compras da empresa, contando com a participação dos compradores responsáveis pelos fornecedores selecionados para participarem do projeto. Observa-se que a realização do planejamento das atividades em conjunto com a gerência é de grande importância para o projeto, pois as ações desencadeadas dependerão dos objetivos claros que serão traçados para o programa e do apoio da empresa compradora, que possui os contatos e a influência junto aos fornecedores. Foi disponibilizada uma equipe de pessoas externas (equipe da universidade) para atuar junto aos fornecedores nas áreas de qualidade, produção e alterações de engenharia. $\mathrm{O}$ trabalho foi desenvolvido utilizando 10 etapas, que são brevemente descritas a seguir.

\section{(1) Identificação da necessidade de melhorias}

Deve ser identificado o contexto que gerou a necessidade das melhorias na cadeia de fornecedores, criando o pré-requisito para implantar o projeto. Em grande parte das situações é útil conhecer o cenário econômico, político e cultural no qual o problema se insere.

No trabalho desenvolvido, esta etapa contemplou compreender o cenário de máquinas agrícolas e, principalmente, as suas diferenças comparado ao setor automotivo. Observa-se que o setor agrícola possui acentuada sazonalidade no comportamento das vendas, é fortemente dependente dos incentivos agrícolas dos governos e sua cadeia de suprimento é formada em grande parte por pequenos e médios fornecedores, diferentemente do setor automotivo.

\section{(2) Estabelecimento dos objetivos do projeto}

Os objetivos podem ser estabelecidos a longo, médio ou curto prazo. Os objetivos de longo prazo dizem respeito à cultura, educação e política da empresa e aos ganhos obtidos pela cadeia de fornecimento com o projeto. Os objetivos de médio prazo dizem respeito à utilização, pelo fornecedor, dos conceitos que serão repassados e que serão replicados no ambiente produtivo de sua empresa. Os objetivos de curto prazo dizem respeito ao resultado que será avaliado no final do período do projeto, tanto junto ao fornecedor quanto junto à empresa.

No trabalho desenvolvido os objetivos de longo prazo deveriam ser alcançados pela empresa. Os mesmos foram: aumentar a competitividade de seus produtos, melhorar a sua cadeia produtiva e alcançar redução de custo dos componentes. Os objetivos de médio e curto prazo foram estabelecidos junto ao fornecedor: utilizar as ferramentas de melhoria disponibilizadas (técnicas de controle de qualidade, seqüenciamento da produção, troca rápida de ferramenta) e obter ganhos em seu processo (redução de retrabalho, redução de custos de matériaprima, aumento de produtividade).

\section{(3) Definição do período de duração do projeto}

O período de duração deve ser definido de acordo com o cenário específico de cada projeto, considerando dificuldades de execução das tarefas tanto para fornecedores quanto para empresa, tempo de resposta, ritmo de trabalho e resultados alcançados até um período. Também poderá ser estabelecido o melhor período no ano para trabalhar junto ao fornecedor, visto que a produção pode ser sazonal.

O tempo de duração proposto, para promover as melhorias nos fornecedores, foi de três meses. Este foi o prazo estipulado para a intervenção propriamente dita, mas novas visitas devem ser realizadas, para consolidar as melhorias propostas e permitir o acompanhamento junto ao fornecedor.

\section{(4) Definição da forma de financiamento do projeto}

Este é um passo muito importante, pois o fornecedor pode estar isento de pagar o projeto e ficar obrigado a alcançar um objetivo estipulado, ou pode pagar parte ou toda a conta. Outra forma que pode ser utilizada é a empresa financiar alguns meses iniciais do projeto, verificar os resultados alcançados e, se os mesmos forem positivos para ambas as partes (fornecedor e empresa), o fornecedor assumirá mais alguns meses de pagamento.

No trabalho desenvolvido, a empresa assumiu o financiamento total do projeto ao longo dos três meses de duração do mesmo. No entanto, possuía intenções claras, discutidas com os fornecedores, de alcançar reduções nos preços dos componentes fornecidos, fruto das melhorias implantadas no processo produtivo.

\section{(5) Definição das informações} disponibilizadas pela empresa

Devem ser definidas com o objetivo de facilitar o encaminhamento das ações necessárias. A disponibilidade de dados, planilhas, desenhos e outros tipos de informações é fundamental para a comprovação dos resulta- 
dos do projeto. É essencial determinar uma pessoa da empresa para acompanhar o projeto ao longo do desenvolvimento e fornecer os dados solicitados.

No trabalho desenvolvido, a empresa disponibilizou dados sobre o desempenho dos fornecedores, referentes a qualidade, custo e entrega (visto que ela tem um boletim de avaliação dos mesmos), informações sobre peças adquiridas (volume, preço, percentual de suprimento) e pessoas para contato interno (engenheiros/ projetistas/ compradores).

\section{(6) Definição da forma de avaliação das propostas submetidas pelos fornecedores}

Deve ser realizada buscando os caminhos mais dinâmicos dentro da estrutura da empresa. Nesta etapa devem ser definidos os responsáveis por julgar as propostas, os prazos para retorno das propostas e as formas de encaminhamento das mesmas (e-mail, telefone, formulário-padrão, serviço de atendimento ao fornecedor, entre outros). Algumas propostas que forem encaminhadas pelos fornecedores e necessitarem de avaliação técnica ou análise de investimento mais elaborada poderão ter seu prazo de resposta estendido. Neste caso sugere-se dar retorno ao fornecedor sobre os motivos da demora.

A execução desta etapa envolveu grande interação entre os profissionais da empresa e a equipe da universidade. Cabe enfatizar que, à medida que o projeto tinha prioridade na empresa, sendo solicitado pela mesma, a resolução das pendências e das demandas do projeto recebeu prioridade e real atenção dos profissionais da empresa. Em alguns momentos, a falta de tempo e as inúmeras atribuições dos profissionais da empresa causaram dificuldade. Nesse sentido, é importante que, no início do programa, seja dimensionada a participação dos profissionais da empresa, assegurando agenda suficiente para atender às demandas que inevitavelmente o projeto irá trazer.

\section{(7) Escolha dos fornecedores participantes do projeto}

Os fornecedores podem ser selecionados pela criticidade de seus processos e operações, seu nível tecnológico, sua importância na cadeia produtiva (participação percentual no conjunto de fornecedores, considerando o volume de vendas à empresa), sua localização geográfica e dificuldade inerente de acompanhamento contínuo do fornecedor, entre outros.

Neste trabalho, os quatros fornecedores que fizeram parte da primeira fase do programa foram escolhidos pela parcela de faturamento junto à empresa, pela dificuldade de relacionamento com a empresa e pela localização geográfica distante e conseqüente dificuldade de acompanhamento.

\section{(8) Identificação do perfil de cada fornecedor}

É importante compreender as inclinações naturais de cada fornecedor, o que inclui identificar seu sistema de qualidade, as tecnologias que utiliza, suas especialidades do ponto de vista de processos e componentes, seu foco principal entre as dimensões custo, entrega e qualidade. Este passo exige confirmação local, pois algumas vezes a percepção da empresa não reflete a real situação do fornecedor. Por outro lado, este passo pode ser de grande importância para o projeto, na medida em que pode dar retorno à empresa do verdadeiro perfil do fornecedor, auxiliando os responsáveis pelas decisões futuras.

No trabalho desenvolvido, a empresa escolheu quatro fornecedores do setor metal-mecânico, produtores de peças em aço, cujo faturamento anual variava entre um e quatro milhões de reais. No início do projeto, a empresa indicou os principais pontos a atacar, informou as peculiaridades do processo produtivo e descreveu o quadro de relacionamento para cada fornecedor. Ao longo do projeto, a percepção da empresa revelou-se correta no caso de dois dos fornecedores. Os demais, no entanto, possuíam um perfil diferente daquele informado originalmente.

\section{(9) Definição da forma de avaliação dos} resultados durante intervenção nos fornecedores

A avaliação dos resultados pode ser realizada através da estimativa de ganhos em forma percentual de um indicador, como, por exemplo, faturamento ou índice de aproveitamento do tempo produtivo que o fornecedor dispõe. Os resultados alcançados após a implementação também podem ser comparados em relação a início do projeto, comparando a evolução e o aproveitamento obtido pelo fornecedor. Por outro lado, alguns resultados de difícil mensuração podem ser considerados, em consenso, como alcançados totalmente ou parcialmente ao final do projeto. Verifica-se grande importância na mensuração numérica dos resultados do projeto, pois a continuidade de novos projetos depende do retorno econômico obtido nos projetos anteriores.

No programa em questão, a empresa, através do suporte da equipe da universidade, optou por quantificar as melhorias na parte de alterações de engenharia das peças, na parte de qualidade e na parte de melhorias alcançadas no chão-de-fábrica, por meio de um indicador financeiro, que traduzia as melhorias em redução no custo de fabricação das peças produzidas. Assim, todas as ações foram avaliadas utilizando uma base comum: retorno financeiro, medido em R \$. Outra peculiaridade deste programa, é que a empresa não obrigou os fornecedores a participar do projeto e a implantar as melhorias solicitadas. Entre- 
tanto, planeja ampliar os pedidos junto àqueles que estão atingindo bons resultados.

\section{(10) Acompanhamento aos fornecedores}

Este acompanhamento pode ser realizado mediante reuniões e visitas às partes envolvidas, sempre que necessário, a fim de sanar as dificuldades e dar encaminhamento rápido às ações necessárias. Num primeiro momento, os fornecedores escolhidos, a empresa e a universidade devem se reunir a fim de expor os objetivos do projeto, formas de atuação, duração e características peculiares, dando início ao trabalho junto aos fornecedores. Num momento final, os mesmos devem ser reunidos novamente a fim de consolidar os ganhos do projeto e verificar a efetividade das ações empreendidas. Algumas reuniões de acompanhamento podem ser realizadas sem a participação dos fornecedores, apenas entre empresa e universidade.

No estudo desenvolvido, os fornecedores foram reunidos na sede da empresa para expor os objetivos do programa e os resultados esperados. Observou-se que os fornecedores demonstraram incertezas quanto à sua participação, quanto aos resultados que deveriam ser alcançados e quanto à forma de avaliação do projeto. Essas incertezas, em grande parte, tinham origem no comportamento passado da empresa, baseado em estabelecer uma relação de benefício unilateral com os fornecedores. Os encontros continuados foram gradativamente diminuindo resistências e esclarecendo as vantagens que ambas as partes poderiam ter com a realização do programa. Ao longo do programa, a empresa acompanhou o desempenho dos fornecedores mediante visitas, relatórios, e-mails e reuniões com as partes envolvidas, sempre que solicitadas. Uma reunião final, com a participação de todos, foi realizada com o intuito de assegurar que as partes possuíam o mesmo entendimento referente às melhorias obtidas e respectiva quantificação financeira.

O programa desenvolvido com a empresa, que no primeiro ano contemplou um conjunto de quatro fornecedores, poderá ser aplicado em outros grupos de fornecedores, estabelecendo uma cultura de melhoria contínua da cadeia de fornecedores.

\section{ETAPAS DO PROGRAMA DE DESENVOLVIMENTO DE FORNECEDORES JUNTO AO FORNECEDOR}

Inicialmente foram realizadas reuniões para exposição dos objetivos do projeto com cada fornecedor. O convencimento da gerência, o compromisso de engajamento dos profissionais de cada área e a predisposição para avaliar alguns investimentos financeiros, são atividades essenciais para o sucesso do projeto.
Devido ao comportamento histórico da empresa, a mesma pode estar desacreditada junto ao fornecedor. Conseqüentemente, o programa de desenvolvimento de fornecedores pode se tornar sem efeito para as duas partes. O fornecedor poderá omitir ou negar informações e, até mesmo, não implementar as sugestões de trabalho. A empresa poderá não dar seguimento às ações que lhe dizem respeito.

As atividades realizadas junto aos fornecedores, em grande parte, necessitam de participação dos responsáveis pelo chão-de-fábrica, supervisores e operadores. A base do método, conforme pode ser visto, está descrita na literatura. O diferencial foram a seqüência das etapas, as condições de contorno adotadas para atingir os objetivos, a participação individual dos fornecedores escolhidos, as atividades que foram sendo desenvolvidas à medida que o projeto evoluiu, caracterizando este trabalho como uma pesquisa-ação.

As etapas realizadas junto aos fornecedores estão organizadas em quatro fases, subdivididas em fase exploratória, caracterizada pelo levantamento de dados genéricos no fornecedor; fase principal, caracterizada pela atuação direta no setor-gargalo escolhido; fase de ação, caracterizada pela implementação de ações no chão-de-fábrica, e fase de avaliação, caracterizada pela verificação dos resultados atingidos no fornecedor.

Para exemplificar as fases acima, foi escolhido relatar as atividades que foram realizadas em um fornecedor participante do programa.

O fornecedor escolhido tem um faturamento de $\mathrm{R} \$ 4,2$ milhões por ano junto à empresa e está localizado a $600 \mathrm{~km}$ de distância da mesma. Fornece cerca de 650 itens para a empresa, a qual consome $70 \%$ de sua produção mensal. Possui 82 funcionários distribuídos entre o chão-de-fábrica e o escritório. É especializado no fornecimento de conjuntos montados estampados em chapas de aço. As atividades deste fornecedor baseiam-se nos processos de corte, dobra, estampagem, soldagem, usinagem, pintura e montagem. O setor que constitui o gargalo da produção é a estamparia, que é composto por quatro prensas excêntricas com aproximadamente 10 anos de uso. As máquinas estão dispostas de acordo com o processamento, ou seja, seguem um layout funcional.

Inicialmente foi realizado um encontro de convencimento e esclarecimento do trabalho para a alta gerência de cada fornecedor. O enfoque do trabalho de redução dos tempos de setup ocorreu no setor de estamparia. Para realizar um diagnóstico da rotina e das atividades do setor foram realizadas observações visuais, acompanhamento dos tempos de setup anteriores ao projeto e filmagem do chão-de-fábrica do setor. A observação visual foi utilizada para gerar um diagnóstico rápido, acelerando o 
encaminhamento do trabalho. O acompanhamento do tempo de setup foi escolhido, pois os problemas de organização do setor, das ferramentas e matrizes, alimentação da máquina e movimentos desnecessários dos trabalhadores poderiam ser analisados conjuntamente no período. A filmagem do chão-de-fábrica foi realizada para analisar os tempos de preparação e auxiliar na construção da solução com os próprios operadores.

De posse do diagnóstico obtido através da observação individual e das filmagens, as pessoas envolvidas no processo e nas operações do setor foram reunidas para discutir alguns conceitos que seriam necessários no desenvolvimento do trabalho. Os conceitos teóricos foram repassados em uma reunião com duração aproximada de três horas, ministrados por um membro da equipe da universidade, da qual participaram seis operadores do setor e o encarregado pela produção. Em linhas gerais, foram abordados os seguintes assuntos: a diferença entre processo e operação tendo como base o sistema japonês de produção, diferenciação entre Just in Case e Just in Time e passos da metodologia de TRF.

Através da filmagem realizada no chão-de-fábrica, foram analisados os problemas de: alimentação, desalimentação, perda por movimentação e realização do setup, identificação dos tipos de setup, distribuição das tarefas no tempo e sugestão de alternativas de realização. Verificou-se intensa participação dos operadores na busca de soluções. Ao final deste encontro, foi designada uma pessoa responsável pela implantação das melhorias no fornecedor, bem como pelos prazos de execução das atividades.

De maneira geral, os pontos positivos, percebidos após a implementação, no setor de estamparia dizem respeito a melhorias no fluxo de peças. Uma mesa central grande que estava situada no centro do espaço entre as máquinas e que continha muitas peças em espera foi retirada. Foram colocadas duas mesas pequenas com rodas ao lado de cada máquina, uma para abastecimento e outra para depositar as peças prontas, conforme pode ser observado na Figura 1. Observou-se diminuição dos movimentos dos trabalhadores e disposição das peças em seqüenciamento adequado de produção. Foi contratada uma pessoa em cada turno para abastecer e desabastecer as mesas auxiliares. Está sendo desenvolvido um "preparador" para as máquinas. Entretanto, devido à exigência de que o mesmo deva ser alguém com bastante conhecimento das peças e das ferramentas envolvidas em cada caso, a otimização desta tarefa irá demorar mais que o período de duração do programa.

$\mathrm{Na}$ fase de avaliação, além da melhora visual, também foi realizada uma estimativa numérica baseada na análise dos tempos alcançados com o trabalho de melhoria nos processos e operações. Calcularam-se dois tipos de ganho: a) o tempo ganho devido à diminuição do tempo de setup (organização do setup, conversão do setup interno em externo, contratação de auxiliares, padronização das alturas), que gerou um tempo "extra" que, havendo pedidos, poderá ser utilizado para produção de novas peças, agregando valor às matérias-primas; $\mathrm{e}$

b) o tempo ganho por diminuir movimentações dos trabalhadores, alimentação e desalimentação das máquinas, desobstrução do setor, organização dos desenhos e peças, que aumentou a produtividade e diminuiu o custo do setor.

Figura 1: Resultados do programa no fornecedor (antes e depois).
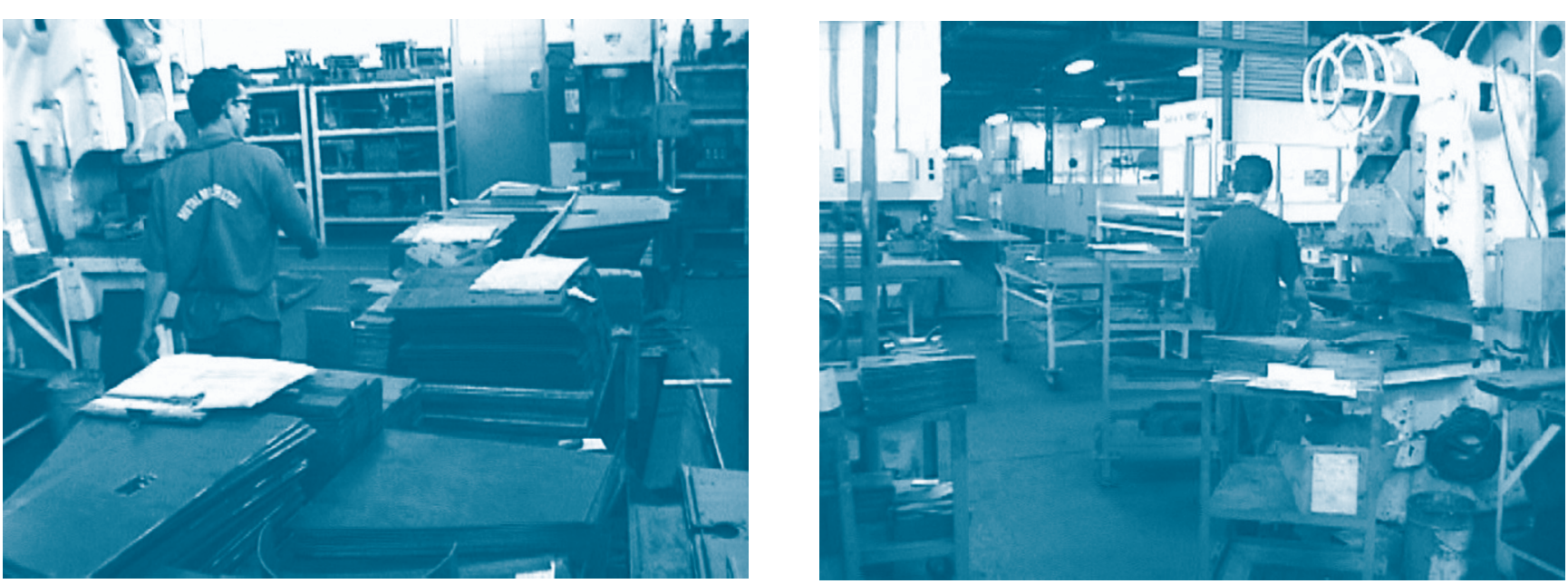
Os ganhos devido à melhoria podem ser visualizados na tabela 1. Nesta tabela, observa-se o tempo de setup antes e depois do projeto.

Pode-se observar que o tempo médio utilizado para setup foi reduzido em 480 minutos por dia. Com a finalidade de exemplificar o que pode ser produzido num determinado tempo e agregar valor, foram acompanhados os tempos de produção de determinadas peças fornecidas à empresa, considerando o tempo que estão em processamento na estamparia, que é o setor gargalo. Como o fornecedor fornece conjuntos montados, tomouse como exemplo o tempo de processamento de todas as peças que compõem um dos conjuntos fornecidos. Observa-se que, em 64 minutos de produção, se produz o equivalente a $\mathrm{R} \$ 145,00$ de peças. Dividindo o tempo ganho pela redução de setup pelo tempo utilizado para processar estas peças, considerando-se lucratividade de $10 \%$, o ganho estimado no mês é de $\mathrm{R} \$ 2.401,00 /$ mês, que provém da melhor utilização do tempo utilizado para preparar a máquina.

O ganho em produtividade foi consensuado em conjunto com os funcionários do setor. Estimou-se que a produtividade aumentou em 15\%, devido a redução da movimentação e aumento de produção. Pode-se considerar que um aumento de produtividade de $15 \%$ deixe de utilizar $15 \%$ do tempo produtivo disponível no mês. Se for utilizada a hora do setor de estamparia $(\mathrm{R} \$ 13,00)$ como base para este cálculo, o fornecedor poderia deixar de produzir 193,90 horas no mês e economizar R\$ 2.519,00 pelo aumento da produtividade.

Descontando-se os custos de contratação dos dois funcionários ( $\mathrm{R} \$ 1.580,00$ por mês), somando-se as parcelas devidas à redução do tempo de setup e ao aumento da produtividade, o fornecedor obteve um ganho mensal de $\mathrm{R} \$ 3.340,00$. Este valor representa aproximadamente $5 \%$ do lucro líquido, se for considerado o volume de vendas mensal, do fornecedor para a empresa, e a respectiva margem de lucro.

Recomenda-se ainda, melhorar aspectos ligados a organização das ferramentas, padronização das alturas e criação de procedimentos para executar o setup. Quanto à conversão do setup interno em externo, de acordo com o encarregado pelas melhorias, estão sendo realizados estudos para adquirir mesas auxiliares ( $\mathrm{R} \$ 5.000,00 /$ cada). Porém o maior problema ainda permanece sendo a mão-de-obra escassa e mal preparada, que necessita de treinamento.

\section{ANTECIPANDO DIFICULDADES}

Prevendo algumas dificuldades que podem surgir, foi elaborada uma lista que está embasada, em grande parte, nas dificuldades observadas ao longo do projeto, visto que as etapas do método foram consolidadas após o trabalho junto à empresa e aos fornecedores. São propostas algumas ações que poderiam minimizar seu efeito, as quais têm ligação com as ações propostas para o futuro, e podem ser visualizadas no Quadro 1.

\section{CONCLUSÕES}

O programa de desenvolvimento de fornecedores aqui exposto surgiu da necessidade de uma empresa do setor de máquinas agrícolas de melhorar o desempenho de seus fornecedores. Este trabalho relatou as etapas que foram utilizadas em um projeto de desenvolvimento de fornecedores. Os passos de aplicação da TRF utilizados em um fornecedor foram descritos e ao final foram estabelecidos os ganhos obtidos, tanto sob o ponto de vista do fornecedor quanto da empresa. As melhorias obtidas com um fornecedor foram quantificadas monetariamente e revelaram um importante retorno sobre o investimento feito pela empresa. Acredita-se que o método pode ser replicado em outros fornecedores, ampliando os ganhos na cadeia produtiva.

As vantagens decorrentes do programa de desenvolvimento de fornecedores são muitas, dentre elas podem ser citadas várias oportunidade para a empresa: (i) conhecer os fornecedores mais detalhadamente, (ii) corrigir procedimentos e práticas que podem auxiliar os fornecedores a obter desempenho superior, (iii) baseada em um diagnóstico mais especializado, encaminhar ações futuras em benefício dos melhores fornecedores, (iv) melhorar a opinião do fornecedor a respeito de suas práticas, anteriormente embasada apenas na redução do custo, e (v) obter melhorias em diferentes áreas de atuação, aumentar sua competitividade e estender os ganhos para toda a cadeia

Tabela 1: Ganho devido a redução de tempo de setup.

\begin{tabular}{|l|c|c|c|c|c|}
\hline & SETUPS/DIA & TURNOS & MÁQUINAS & TEMPO MÉDIO & DESPERDícIO \\
\hline Antes & 8 & 2 & 4 & 15 minutos & 960 minutos/dia \\
\hline Depois & 8 & 2 & 4 & 7,5 minutos & 480 minutos/dia \\
\hline
\end{tabular}


Quadro 1: Dificuldades do programa de desenvolvimento e soluções propostas.

\begin{tabular}{|c|c|}
\hline DIFICULDADES & PREVENÇÃO \\
\hline $\begin{array}{l}\text { Escolha inadequada } \\
\text { dos participantes } \\
\text { do programa e falta } \\
\text { de motivação }\end{array}$ & $\begin{array}{l}\text { Permitir ao fornecedor manifestar desejo de participar ou não do programa; } \\
\text { Avaliar o fornecedor individualmente quanto a necessidades e capacidades; } \\
\text { Selecionar fornecedores capazes de cumprir os objetivos a curto e médio prazo; } \\
\text { Compreender o momento vivenciado pelo fornecedor e entender suas motivações. }\end{array}$ \\
\hline $\begin{array}{l}\text { Indisponibilidade de } \\
\text { tempo }\end{array}$ & $\begin{array}{l}\text { Aumentar a motivação para o trabalho, explicitando ganhos e vantagens que serão obtidos } \\
\text { com o melhor aproveitamento do tempo no futuro; } \\
\text { Enfatizar que o programa possui maior ênfase e necessidade de mudanças nos três meses } \\
\text { iniciais. Finalizado este prazo, as rotinas estarão implementadas e deverá ser realizados } \\
\text { apenas o acompanhamento e a melhoria contínua. }\end{array}$ \\
\hline $\begin{array}{l}\text { Indisponibilidade } \\
\text { para realizar } \\
\text { investimentos }\end{array}$ & $\begin{array}{l}\text { Priorizar os investimentos de baixo custo; } \\
\text { Avaliar o custo-benefício dos investimentos necessários; } \\
\text { Definir o payback para os investimentos maiores. }\end{array}$ \\
\hline $\begin{array}{l}\text { Consolidação dos } \\
\text { ganhos obtidos }\end{array}$ & $\begin{array}{l}\text { Estabelecer uma forma de avaliação dos ganhos e mensurar todos os fornecedores com o } \\
\text { mesmo parâmetro; } \\
\text { Definir uma rotina de acompanhamento ao fornecedor auxiliando-o sistematicamente após o } \\
\text { fim do projeto; } \\
\text { Instrumentalizar os fornecedores, ao longo do programa com material didático apropriado } \\
\text { para incorporar as propostas ao cotidiano da empresa. }\end{array}$ \\
\hline
\end{tabular}

produtiva. Adicionalmente, talvez tão importante quanto os ganhos financeiros, também foi observado um estreitamento nas relações empresa/fornecedor, facilitando projetos futuros.

É essencial que a empresa dê continuidade às ações iniciadas com fornecedores, permitindo que as ações empreendidas durante o projeto sejam incorporadas como práticas comuns e rotineiras. Isso irá aumentar a confiança dos fornecedores quanto aos objetivos da empresa, melhorando o relacionamento entre as partes.
À medida que o projeto for estendido a outros grupos de fornecedores, torna-se importante estabelecer uma rotina de acompanhamento dos fornecedores que participaram do projeto no passado. Este acompanhamento visa consolidar a utilização das técnicas implementadas, instrumentalizar os recursos humanos que trabalham junto aos fornecedores e redefinir novos caminhos de atuação que se fizerem necessários, tanto nos fornecedores quanto na empresa.

\section{Artigo recebido em 05/09/2003 Aprovado para publicação em 09/01/2004}


BIEHL, R.E. Customer-Supplier Analysis in Education Change. Quality Management Journal. v. 7, n. 2, p. 2239, 2000.

BLENKHORN, D.L.; LEENDERRS, M.R Reverse Marketing: an Untapped Strategic Variable. Business Quarterly, v. 53 , n. 1 , p. $85-89,1988$

CAMPOS, V. F. Controle da Qualidade Total (No Estilo Japonês). Belo Horizonte: Fundação Christiano Ottoni, 2 ed., 220p, 1992.

CHANDRASHEKAR, A.; CALLARMANN, T.E. A Modeling Study of the Effects of Continuous Incremental Improvement in the Case of a Process Shop. European Journal of Operational Research, v. 109, n. 1, p.111-121, 1998.

CARTER, J.R.; SMELTZER L.; NARASIMHAN, R. The Role of Buyer and Supplier Relationships in Integrating TQM through the Supply Chain. European Journal of Purchasing e Supply Management, v. 4, n. 4, p.223234, 1998.

CRAWFORD, K.M.; COX, J.F. Addressing manufacturing problems through the implementation of Justin-time. Production and Inventory Management Journal, v. 32, n. 1, p. 3336, 1991.

DE TONI, A.;NASSIMBENI, G. Just-intime Purchasing: am Empirical Study of Operational Practices, Supplier Development and Performance. Omega, v. 28, n. 6, p. 631-651, 2000.

GRIFFITHS， J.; MARGETTS D Variation in Production Schedules Implications for Both the Company and its Suppliers. Journal of Materials Processing Technology, v. 103, n. 1, p. 155-159, 2000.

GUANASEKARAN, A.; CECILLE P. Experiences on Small Company in Productivity Improvements. Production and Inventory Management Journal, v. 39, n. 2, p. 49-54, 1998.
HAHN, C.K.; WATTS, C.A.; KIM, K.Y. The Supplier Development Program: a Conceptual Model. Journal of Purchasing and Materials Management, v. 26, n. 2, p. 2-7, 1990.

HANDFIELD, R.B.; KRAUSE, D.R. SCANELL, T.V.; MONZKA, R.M. Avoid the Pitfalls in Supplier Development. Sloan Management Review, v. 41, n. 2 , p. $37-49,2000$

HAY, E.J. Any Machine Setup Time Can be Reduced by $75 \%$. Industrial Engineering, v. 19 , n. 8, p. 62-66, 1987.

HUMPHREYS, P.K; SHIU, W.K.; CHAN, F.T.S. Collaborative Buyer-Supplier Relationships in Hong Kong Manufacturing Firms. Supply Chain Management: An International Journal, v. 6, n. 4 , p. 152-162, 2001.

KANNENBERG, G. Proposta de Sistemática para Implantação de Troca Rápida de Ferramentas. Porto Alegre. Dissertação (Mestrado em Engenharia de Produção). Escola de Engenharia, Programa de PósGraduação em Engenharia de Produção, Universidade Federal do Rio Grande do Sul, 1994.

KEOUGH, M. Buying ou way to the top. Director, v. 47 , n. 9 , p. $72-77$, 1994.

KRAUSE, D. Supplier Development: Current Practices and Outcomes. International Journal of Purchasing and Material Management,v. 33, n. 25, p. 12-19, 1997.

KRAUSE, D. The Antecedents of Buying Firm's Efforts to Improve Suppliers. Journal of Operations Management, v. 17, n. 2, p. 205-224, 1999.

KRAUSE, D.; ELLRAM, L. M. Critical elements of Supplier Development. European Journal of Purchasing and Supply Management, v. 3, n. 1, p. 2131, 1997a.
KRAUSE, D.; ELLRAM, L. M. Success Factors in Supplier Development. International Journal of Physical Distribution and Logistics Management, v. 27, n. 1, p. 39-52, 1997b.

KRAUSE, D.R.; HANDFIELD, R.B.; SCANELL, T.V. An Empirical Investigation of Supplier Development: Reactive and Strategic Process. Journal of Operation Management, v. 17, n. 1, p. 39-58, 1998.

LEENDERS, M.R. Supplier Development. Journal of Purchasing and Material Management, v. 25, n. 1, p. 4755, 1989.

MCINTOSH, R.I.; CULLEY, S.J.; MILEHAM A.R; OWEN, G.W. A Critical Evaluation of Shingo's SMED (Single Minute Exchange of Die) Methodology. International Journal of Production Research, v. 38 , n. 11 , p. $2377-2395,2000$.

MILGATE, M. Supply Chain Complexity and Delivery Performance: an International Exploratory Study. Supply Chain Mangement: an International Journal, v. 6, n. 3 , p. 106-118, 2001.

MOHR, J.; SPEKMAN, R. Characteristics of Partnership Success: Partnership Attributes, Communication Behavior, and Conflict Resolution Techniques. Strategic Management Journal, v. 15, n. 2 , p. 135-152, 1994

MOXHAM, C.; GREATBANKS, R. Prerequisites for the Implementation of the SMED Methodology - A Study in a Textile Processing Environment. International Journal of Quality e Reliability Management, v. 18 , n. 4 , p. 404-414, 2001.

NEUMANN, C.S.R. Desenvolvimento de Fornecedores um Estudo de Caso Aplicado ao Setor de Máquinas Agrícolas. Porto Alegre. Dissertação (Mestrado em Engenharia de
Produção). Escola de Engenharia, Programa de Pós-Graduação em Engenharia de Produção, Universidade Federal do Rio Grande do Sul, 2002. http:///www.producao. ufrgs.br/Banco_Teses/Result_BT.asp

PATEL, S.; SHAW, P.; DALE, B.G. Setup Time Reduction and Mistake Proofing Methods - A Study of Application in Small Company. Business Process Management Journal, v. 7, n. 1, p. 66 $75,2001 \mathrm{a}$

PATEL, S.; SHAW, P.; DALE, B.G. Setup Time Reduction and Mistake Proofing Methods - An Examination in Precision Component Manufacturing. The TQM Magazine, v. 13, n. 3, p. 175179, 2001b.

REHMAN, A. e DIEHL, M.B. Rapid Modeling Helps Focus Setup Reduction at Ingersoll, Industrial Engineering, v. 25, n. 11, p. 52-55, 1993.

SHINGO, S. Sistemas Toyota de Produção: do Ponto-de-Vista da Engenharia de Produção. Tradução de Eduardo Schaan. Porto Alegre: Bookmann, 291p, 1996a.

SHINGO, S. Sistemas de Produção com estoque zero: O Sistema Shingo para melhorias contínuas. Tradução de Lia Weber Mendes. Porto Alegre: Bookmann, 380p, 1996b.

SHINGO, S. Sistema de Troca Rápida de Ferramenta: uma Revolução nos Sistemas Produtivos. Tradução de Eduardo Schaan e Cristina Schumacher. Porto Alegre: Bookmann, 327p, 2000.

STUART, F.L.; MCCUTCHEON, D. Sustaining Strategic Supplier Alliances - Profiling the dynamic requirements for continued development. International Journal of Operations e Production Management v. 16, n. 10, p. $5-22,1996$.

VENJARA, Y. Setup Savings Manufacturing Engineering, v. 117 n. 1, p. 96-102, 1996. 